\title{
4 \\ A bias for action? The military as an element of national power
}

\author{
John J. Frewen
}

Australia's military instils in its members a 'can-do' culture with a bias for action, inculcated early in the careers of virtually all officers and enlisted personnel. This ethos seeks both to ensure that opportunities are seized and to avoid the more common historical peril of inaction. This instinct serves us well on the battlefield; it can be be of less benefit at the operational and strategic levels where consequences of decisions tend to be more farreaching. This bias is not merely a military concern. The public can also demonstrate a bias for action without due consideration of the broader political issues at stake. Depending on the circumstances, politicians can also demonstrate bias for either action or perceived action. Regardless, the Australian Defence Force (ADF) is a relatively well-resourced and capable asset available to governments for a broad range of contingencies. From high-intensity warfighting to humanitarian operations, the ADF can be rapidly brought to bear to satisfy the ends of policy-uniquely in our government, through the employment of armed force. Yet, while the ADF can contribute to Australia's national security, it cannot alone deliver national prosperity.

Realising a nation's potential requires considered thought about how to best utilise all the assets at its disposal. This is most readily achieved with a clear view of the nation's highest aims and a strong sense of the risks and costs that can be accepted in their pursuit. Strategy—-the art of aligning 
ends, ways and means-is the surest path for defining those conditions. The use of military force entails profound risks, including the potentially pointless loss of life. This risk tends to be more acute if military elements are used in isolation from other instruments at the nation's disposal. Nevertheless, a bias for military action remains evident in both the military and government even if the underlying motivations sometimes differ. This chapter explores the implications of a bias for military action on the making of strategy in Australia and on the military as an institution and important element of national power.

The making of effective strategy is one of the most complex and difficult aspects of government work. And although there are many capacities within government to develop strategic policy, it is important not to confuse policy with strategy. Policy is a statement of principles intended to guide actions. Strategic policy requires strategies to harness national instruments of power in the service of political objectives. In general, the best strategies are those that integrate all the elements of national power: the diplomatic, information, military, economic (DIME). ${ }^{1}$ These elements can be prioritised differently depending on the circumstances, but integration is usually key to achieving the best effect, especially in complex endeavours.

\section{Who does strategy?}

In the Australian Government, and arguably in most comparable Western democratic bureaucracies, there is a stark contrast between the large number of people whose job involves contributing to the making of strategy and the relative absence of government bodies dedicated to formulating strategy as a whole. This is problematic because it disaggregates the strategy-making process to such an extent that it precludes the level of coherence needed to be effective.

While the Department of Prime Minister and Cabinet is meant to provide direction, no single entity within the Australian Government is presently tasked to routinely deliver national strategies that integrate all elements of national power. Extant government agencies and departments are geared to delivering policies or assessments. Policies are routinely well agreed and

1 An alternative national power model to DIME also includes financial, intelligence and law enforcement (DIMEFIL). 
aligned across departments before consideration by the political executive, but only extraordinary circumstances drive governments to deliver national strategies that bridge the gap between policy and outcomes. Actual strategy clearly defines the political imperative (ends), parameters for action (ways) and the resources that may be utilised or expended (means). Unfortunately, for Australia, our strategic culture has long relied on a powerful ally to set overarching grand strategy, which denudes the capacity for coherent or sensible formulation of strategy here at home.

Other systemic issues stymie the long-term thinking and planning required for strategy as well. Our federal three-year electoral cycle, the 24-hour news cycle and a growth in populist politics lead us towards short-termism in policy. Similarly, our key decision-making bodies, including federal parliament and the National Security Committee of Cabinet (NSC), by their natures also have a proclivity for near-term-if not immediate- resolution of matters without the consistent setting of clear national aims or ideas about the integration of separate elements of national power. The resultant processes create systemic myopia in which government scrambles from one issue to the next, typically without prolonged consideration. For example, rarely does government pause to consider alternative scenarios to contest the wisdom of certain chosen courses or pay due consideration to the inevitable action/reaction cycles of complex strategic decisions.

This is not to say that Australia cannot make strategy at all. One example is the implementation of Operation Sovereign Borders (OSB) to cease the unauthorised arrival of people to Australia by boat. Regardless of whether one agrees with the morality of the approach, OSB provides an example where political will is married with a comprehensive integration of a wide range of national instruments to produce a successful political effect. ${ }^{2}$ This is an example of national strategy delivering sustained political objectives against an adaptive adversary. However, it is a rare example and far more the exception than the rule.

2 Operation Sovereign Borders (OSB) employs diplomatic, intelligence, informational, law enforcement, economic, maritime and defence effects. All are individually crucial but are also interdependent on the other elements for success. 
At the other end of the spectrum, the UK's Chilcot Report ${ }^{3}$ provides a timely counterexample of military forces being employed in costly and uncoordinated ways. The report paints a disturbing picture of military commitments almost devoid of a coherent national strategic narrative.

\section{The rush to action}

The use of military power is problematic in a political environment that routinely privileges quick outcomes. Military forces can be employed overtly and almost immediately in pursuit of political ends. Because of the ready utility of armed forces, many forms of military action can be taken quickly — even in the absence of a fully developed strategy. The ADF can, at times, be used as a force of convenience rather than a force of necessity. This can be appropriate and successful in the resolution of small-scale emergencies, such as rescues or evacuations, but can also find nations mired in increasingly costly financial and mortal endeavours in situations that elude straightforward resolution or extraction. ${ }^{4}$ The ready availability of military forces, coupled with a can-do military culture, and politicians eager for quick responses can see military forces too easily deployed with military practitioners and politicians equally complicit.

Senior military officers are enthusiastic about demonstrating the utility and quality of Defence capabilities and are justifiably proud to see the men and women of the ADF succeed in difficult circumstances. However, their enthusiasm is diminished when operations are not supported by appropriate national strategies. Frustrations arise at the tactical level when strategic directives lack clear political objectives or a tangible military end state. Military concerns are compounded if political risk aversion also leads to impractical constraints on military operations (such as excessive restrictions on the employment of national assets within a coalition or a stipulation that there be no casualties). Military resolve is most challenged when an inappropriate level of resourcing for operations or

3 United Kingdom Cabinet Office, The Report of the Iraq Inquiry [Chilcot Report], 6 July 2016, www.gov.uk/government/publications/the-report-of-the-iraq-inquiry (retrieved 16 January 2018).

4 The American war in Vietnam is an example of primarily military action being commenced for initially limited aims before a doubling-down effect took hold to justify expenditure and losses and avoid a loss of national prestige. 
a lack of commitment to achieving military victory risks lives without strong purpose. In recent decades, many now-senior officers have experienced each of these problems.

The ADF maintains a broad range of platforms and capabilities. These forces are highly responsive and willing, and have a planning culture that supports rapid employment. These combine to make the ADF one of the government's instruments of first resort. Military forces present political leaders with rapid and tangible means to display resolve. A political bias for action becomes problematic when military capabilities are not effectively orchestrated with the other elements of national power, when the opportunity costs of utilising military assets rather than civilian assets are not considered, or when military personnel and equipment are either required to use force or are put at risk when some other national instrument could achieve the same effect. That no single entity in government is tasked to evaluate the relative merits of national assets or to ensure such integration via the development of overarching national strategies means that Australian military forces risk being deployed in suboptimal ways.

\section{Parameters of force}

The employment of military force should always be subordinate to policy, itself embedded in a firm conception of the national interest. What national interest is to be served? Is the use of military assets optional or vital (such as in the face of an existential threat)? Is the use of force necessary for the achievement of the task? Is the intended effect symbolic or substantive? Will we be acting unilaterally, be leading a coalition or be junior partners within a coalition? If in a coalition, will our military contribution be proportionate? What degree of integration will there be with other agencies? Do we understand the consequences and likely effects of the use of military forces? What is our tolerance for risk in relation to our forces and platforms? To complicate matters further, moreover, these considerations can change during an operation. For example, force might be required early in a mission but not later on. While these considerations do illustrate the complexity of military operations, and may temper the rush to use force, they cannot altogether ensure that decisions to employ military forces will be free of bias. 
The risks inherent in military commitments tend to be lower in the absence of an armed adversary. For example, the recent Operation Fiji Assist 2016-a humanitarian task with no requirement for use of forcesaw military forces acting in concert with the Department of Foreign Affairs and Trade (DFAT) and New Zealand counterparts. Together, they quickly helped facilitate relief for the people of Fiji in response to the havoc wreaked by Tropical Cyclone Winston. The ADF also very effectively acted as ambassador for Australia and were subsequently extracted in a timely and appropriate way after having reinforced Australia's standing in the region.

In 2003, the Regional Assistance Mission to Solomon Islands (RAMSI) similarly saw ADF forces supporting DFAT and the Australian Federal Police (AFP) in security operations to restore law and order during troubled times that included confronting potentially dangerous armed opponents. RAMSI demonstrated effective integration of the elements of Australia's national power to avoid the emergence of a regional failed state. Australia's efforts again enhanced the country's reputation as a good neighbour and partner in the Pacific despite achievement of strategic objectives proving costlier in time and dollars than was originally anticipated. Arguably, our commitments in both Solomon Islands and Fiji were not optional or discretionary but central to our longer-term regional interests. Conversely, the benefits of our recent deployments into war zones have been less apparent.

Australian operations in Iraq in 1990-91 and since 2002 in Afghanistan can be argued as discretionary operations in which alliance considerations outweighed any threats to Australia's direct interests. In these cases, ADF forces (other than special forces) were largely confined to limited combat operations designed to minimise the likelihood of casualties and avoid circumstances that might restrict Australia's ability to extract forces at the time of its choosing. Although force was a necessary component of these missions, it was not required to attain Australia's preferred policy outcomes, nor was it essential to achieving military victory. Indeed, what exactly constituted 'military victory' was not well defined and was left largely in the hands of US or North Atlantic Treaty Organization (NATO) mission heads. In these cases, military force was employed more to support the US alliance, and thereby sharpen an instrument in Australia's national security toolbox, than in direct defence of any vital 
national interest. Notwithstanding the importance of the US alliance for Australia, in both these cases military efforts were not consistently well integrated with other elements of national power.

To focus on the case of Afghanistan, the ADF-led Australian efforts to establish security, develop civilian capacity and support local governance in Oruzgan Province. Supported by DFAT, AFP efforts focused on counter-drug operations despite the lack of an effective local Afghan police force or a viable program to develop such a capability. Australian on-theground commitments were in consequence not in keeping with strategic objectives. ADF operations did contribute to denying insurgents a safe haven more broadly (as do our ongoing efforts). Yet more than a decade later it is difficult to portray a compelling case that the country's efforts have provided an enduring effect.

The most enduring aspect of Australian commitments in both Afghanistan and Iraq is the affirmation of a commitment to our major ally in matters of global concern and of our support to troubled nations in times of crisis. Australian military presence was arguably more significant in an alliance sense than was any combat success or nation-building outcome they achieved. Australia's military efforts in Iraq and Afghanistan reinforced our reputation as a good global citizen, one committed to a rules-based world order. Yet actions in both countries lacked a strategy effective in integrating Australia's broader government commitments for achieving anything beyond 'showing the flag'. Perhaps, however, no strategy was needed given that mere presence was sufficient to achieve the strategic objective of reinforcing the Australia-US relationship.

\section{Policy conundrums}

This modern phenomenon, whereby the deployment of military forces can be the policy outcome itself, presents four conundrums. The first is that this style of employment of military force belies the traditional model of strategy as a bridge that links means with ends. This seems more like using means to secure other means. The second is that strategic policy is increasingly supplanting national strategy with implications that are not well understood. Third, military force is being used in isolation from other elements of national power, which rarely delivers sustainable outcomes. Finally, military personnel are at risk of being killed or wounded to bring about policy goals that could be achieved in other, less risky ways. 
As mentioned, the Australian Government is currently geared to formulate strategic policy, but not strategy per se. We are a policy-led bureaucracy in which the coin-in-trade is position papers and assessments presenting options to government. Strategic policy discussions and papers typically touch on principles for endorsement, recommended diplomatic stances, possible actions or responses in a broad sense, and discussion of risks and the ways they might be mitigated. These are often enough for guiding the routine relationships and business of government in a set-and-forget manner, but they are not sufficient for managing situations where some vital national interest is genuinely threatened. This is where policy falls short of strategy in defining the interrelationship of ends, ways and means, and where policy-makers fall short of the requirement for strategists to make plans in an interactive and competitive context. The dominance of strategic policy over strategy is also how we also continue to risk a 'rush to action' that favours rapid and highly visible military commitments without fully defined, longer-term national aims or integration with other elements of national power.

In a crisis, doing something is often seen as a common imperative. The high-readiness of military assets makes them available early in any crisis, but there are other reasons that government tends to reach for the military first. Military units and formations are structured to operate and sustain themselves independently if necessary. They are also trained to operate with restrictions, limitations and caveats on their authorities and activities - and have a culture that anticipates constant shifts in guidance. Government decisions can be quickly turned into orders and military forces moved out. Other elements of national power are rarely as responsive. Diplomatic agreements must be negotiated and coordinated. Informational activities can have immediate effects but can also require broad consultation and careful timing in ways that preclude immediacy. Economic or fiscal measures require agreement and can have unpredictable (and often delayed) effects. If being seen to take timely action is a priority, the military is the instrument of national power that can act before other elements of national power are effectively brought to bear. However, the non-integrated use of military force rarely delivers sound long-term solutions to a crisis.

The example of RAMSI demonstrates a comprehensive whole-ofgovernment attempt to restore security, law and order, good governance, a functioning justice sector and sustainable economy concurrently to a failing nation. After a decade, RAMSI has delivered sound results and has 
Solomon Islands once again effectively managing its own destiny, albeit with some way still to go. In Iraq, and to a lesser extent in Afghanistan, a more linear-if not traditional-approach of military action with sequential transition to other aspects of national development sees Iraq and Afghanistan still dependent on international aid and assistance more than a decade after the initial military-led interventions and uncertain whether their governance and justice sectors can become effective or their economies can ever be self-sustaining. A bias for military action can mean a bias for incomplete solutions to international issues. Military actionfrom humanitarian support to warfighting-without complementary other-agency actions risks a limited prospect of resolution and can prolong, or worsen, some circumstances.

The final concern with defaulting to military responses without comprehensive guiding strategies is a moral one. Just as the use of force by governments should be a last resort rather than a first impulse, governments have an obligation to put members of the armed forces at risk of injury or death only for justifiable reasons. In his Quarterly Essay, 'Firing line: Australia's road to war', James Brown portrays our national mechanisms for going to war as lacking the necessary institutional rigour. ${ }^{5}$ While he focuses on the way such 'grave' decisions are made-rather than how strategy is managed-his concern is that these decisions should be grounded in public trust and democratic legitimacy. Aside from the 2003 invasion of Iraq, contemporary commitments of military forces have had firm legitimacy within international laws and conventions. However, those same commitments, including combat roles, have generally maintained bipartisan support and have not been the subject of open debate within parliament before deployment.

\section{Getting it right}

The public have, in general terms, accepted that the use of the military has been appropriate and necessary even as Australian casualties mounted in Afghanistan from 2007 to 2012. Although Australia is unlikely to experience a Chilcot-style enquiry regarding Australia's path into Afghanistan, further deterioration in the circumstances in Oruzgan Province might provoke deeper thought about what Australia's strategy

5 James Brown, 'Firing line: Australia’s road to war', Quarterly Essay 62, 2016, pp. 56-8. 
was and what the sacrifices there achieved. It is also likely that there will be a greater call for justification to families of the fallen. Our current process for developing national strategy and for deciding to commit forces to combat do not deliver clear articulation of why physical risks are necessary and just how much we are willing to sacrifice. Attempts to define this before combat commitments would likely demand clearer communication of overarching strategy in support of policies and a clearer statement of what military forces are required to achieve-beyond supporting policy by deployment alone. Military force should always be a political means, not a political end.

The next half-century promises to be one of profound global change. In Australia's own region, we are witnessing the rise of China and India and challenges to a US-led, unipolar order that has maintained relative stability for the last 70 years. While India and China's economies are growing, no Western democratic economies_-including Australia's—indicate similar sustainable growth paths. The most significant expansion in workingage populations will be centred on the African continent in this same timeframe. Access to sophisticated military weaponry and technology is becoming cheaper and easier even for non-state entities. Whether we like it or not, Australia's current relative demographic, economic and military advantages will decline in the decades ahead. Addressing this will require deliberate and careful efforts on a national level. Policy, planning and execution of national strategies will be required to retain or maximise Australia’s advantages.

Strategy, by its nature, is ultimately implemented in a competitive environment and should assume that competitors and adversaries will bring all relevant capabilities into play to achieve desired outcomes. Strategy should also assume that setbacks will occur. Because strategy is competitive, not all its elements can be resolved or discussed in the public domain. While policy objectives might be the subject of open debate, strategies require concealed elements such as which assets are to be employed (means), what tactics will be employed (ways) and what risk tolerances will be acceptable in achieving national goals (aims). Coordination of the elements of national power is difficult during strategy formulation and can be even more so during implementation. A further complication is the requirement to integrate strategies either with allies or coalition strategies and with non-government organisations. Each of these requires specialist practitioners and continued attention, which are not well met by ad hoc mechanisms and relationships. 
As discussed, no area of government is presently tasked to look ahead and to recommend strategy beyond the realm of policy. This needs to change if Australia is to maintain our current influence in an increasingly complex and competitive global order. The successful example of OSB initially necessitated the appointment of a three-star military officer to develop and implement an effective strategy. This has since evolved with the creation of Border Protection Command integrated into the Department of Immigration and Border Protection to manage the full gamut of customs and border security concerns. Early successes notwithstanding, achieving the stated policy objective of ceasing unauthorised maritime arrivals to Australia requires the continued active participation of nearly all other government departments, including the stewardship of the Department of Prime Minister and Cabinet (PM\&C) during implementation of the related strategy. The myriad emerging challenges to each of Australia's elements of national power alone-diplomatic, informational, military and economic - in a world of transnational threats and shifting power balances requires national strategies guiding employment of capabilities beyond those that any one government department can deliver.

In 'Firing line', James Brown argues for the establishment of a body to oversee the commitment of military forces to war. ${ }^{6}$ Although this might be beneficial, the incidence of such commitments is fortunately rare and could be handled in an ad hoc or as required manner. The requirement for national strategies is an enduring one, and it is extraordinary that no entity exists to manage this in Australia. Perhaps more surprisingly, our closest major allies, the United States and United Kingdom, have come to the same conclusion: that they also lack effective mechanisms in this regard. A 2014 RAND report, Improving Strategic Competence: Lessons from 13 Years of War, concluded that the United States suffers from a lack of civilian-military mechanisms for developing national security strategy. ${ }^{7}$ As a result, they have conducted military campaigns without an adequate overarching political strategy. Similarly, a 2010 UK House of Commons report, Who Does UK National Strategy?, identified little evidence of sustained strategic thinking or a civilian-military mechanism

6 Ibid., p. 56.

7 Linda Robinson, Paul D. Miller, John Gordon IV, Jeffrey Decker, Michael Schwille and Raphael S. Cohen, Improving Strategic Competence: Lessons from 13 Years of War, RAND, Santa Monica, 2014. 
for strategic analysis and assessment. ${ }^{8}$ The report went on to cite a lack of development or education of strategic thinkers within academia or government institutions. A similar audit in Australia would identify that we are formally no better off.

To better face this future, Australia would be well advised to develop an Office of National Strategy. It is unlikely that the government would see fit to expand government bureaucracy and establish another entity akin to the Office of National Assessments (ONA), but this would be optimal. Non-government bodies such as think tanks might be commissioned to develop strategy but are not well suited to managing its implementation in a continuous sense. An ONA-like organisation could provide the ability to develop classified strategies for government approval-either on their own initiative or at government direction-and could assist in managing implementation with regular feedback to Cabinet or the NSC. An organisation of similar size to ONA could provide sustainable career paths for a growing body of trained strategists from all agencies. Failing this, the next best alternative would be to establish a team within PM\&C that could convene as required. This group, comprising trained strategists from a range of agencies and disciplines, could provide more consistent oversight of national strategy development and implementation than is presently available to the government. Either of these entities would enhance Australia's current ability to prepare for the future beyond the predominantly short-term focus of governments or the tides of passing popular sentiment. An Australian Office of National Strategy could also ensure that more fulsome decisions are taken about committing Australian military forces and with greater regard to the integration of other elements of national power.

\section{Muddling on}

Australia's circumstances will, in all likelihood, become more complicated and challenging in the next few decades. Australia has many relative advantages both regionally and globally. These will progressively erode without strategies that seek to maximise the advantages inherent in effectively applying the instruments of our national power. Without

8 Public Administration Select Committee, Who Does UK National Strategy? First Report of Session 2010-11, UK House of Commons, Stationery Office, London, 18 October 2010; publications. parliament.uk/pa/cm201011/cmselect/cmpubadm/435/435.pdf (retrieved 29 January 2018). 
a body to develop and implement national strategies, response to crises tends to be reactive rather than planned. This, paired with a bias for action, risks the military —as the most responsive and visible instrument of government - being deployed without clear definition of the intended purpose or being fully integrated with the other elements of national power-and unlikely to deliver an enduring solution. In Australia's case, incremental 'muddling through' has not resulted in circumstances as dire as those criticised in the United Kingdom's Chilcot Report. However, in the enduring absence of a formal mechanism for national strategy, the potential is there if Australia were to become embroiled in an existential crisis.

To re-emphasise, the commitment of military forces should be a component of strategy and not an end itself. Force has its place as an enabler of policybut force alone cannot deliver enduring solutions. Its application should be one means among others to deliver sustainable solutions. Accordingly, national strategies should be just that-strategies—and not strategic policy in the guise of strategy. We need strategy as the bridge from policy to action. Military forces should deliver strategic aims due to necessity, not convenience. To ensure this, we need to foster a greater understanding of the elements of national power and their interrelationships, including the limitations on the utility of military forces. We need to ensure that the strategic dialogue between politicians, bureaucrats, military officers and the public is informed and frank.

Australia has more frequently employed military power appropriately in concert with other agencies in recent years. However, the temptation remains to send the military when rapid action is required. Systemic risk remains that we can race from policy to action without a strategy. While remaining policy driven, we must understand that policy alone is not strategy and that a bias for action is not strategic. Our bias should be for action through national strategies that integrate all the relevant elements of national power. We need to help governments to be strategic. To that end, we need greater investment in bodies to develop strategy, create more strategists and grow a national strategic culture that can best protect Australia's future. This will also help Australia find its sweet-spot as a middle-weight military power in an increasingly challenging region and world. 
This text is taken from New Directions in Strategic Thinking 2.0:

ANU Strategic \& Defence Studies Centre's Golden Anniversary

Conference Proceedings, edited by Dr Russell W. Glenn, published 2018 by ANU Press, The Australian National University, Canberra, Australia. 